\title{
Angiopoietin-2 promotes ER+ breast cancer cell survival in bone marrow niche
}

\author{
Hyun Ho Han,2, Baek Gil Kim², Joo Hyun Lee1, Suki Kang², Ji Eun Kim \\ and Nam Hoon Cho1,2,3,4
}

'Brain Korea 21 Plus Project for Medical Science, Yonsei University College of Medicine, Seoul, South Korea 2Department of Pathology, Yonsei University College of Medicine, Seoul, South Korea

3Severance Biomedical Science Institute (SBSI), Yonsei University College of Medicine, Seoul, South Korea ${ }^{4}$ Global 5-5-10 System Biology, Yonsei University, Seoul, South Korea

Correspondence should be addressed to $\mathrm{N} \mathrm{H}$ Cho

Email

cho1988@yuhs.ac

\begin{abstract}
In estrogen receptor-positive (ER+) breast cancer, it is recognized that metastases may develop after a long period of dormancy. Bone marrow (BM) vascular niche is where the dormant tumor cells are most likely to reside. So far, it is not fully understood why the dormant tumor cells become proliferative and eventually generate tumor. We hypothesized that therapeutic or menopause-related estrogen depletion may be the switch behind dormant ER+ tumor cell awakening in BM. We utilized an existing experimental model of BM endothelial niche that can simulate ER+ tumor cell dormancy to test our hypothesis. In results, estrogen depletion paradoxically promoted ER+ tumor cell proliferation in the BM endothelial niche, and their molecular phenotype shifted from dormant to awaken. Following estrogen depletion, the BM niche cells produced angiopoietin-2 (ANGPT2), which destabilized niche endothelium by interfering ANGPT1/Tie2 signaling, and promoted ER+ tumor cell survival under estrogen deficiency via cell surface integrin $\beta 1$. Knockdown of ANGPT2 completely negated ER+ tumor cell awakening in the niche. Furthermore, ANGPT2 expression in ER+ tumor human samples was associated with increased risk of distant metastasis only in those who underwent adjuvant estrogen depletion therapy, not in those who did not undergo adjuvant therapy. In conclusion, we demonstrate that ANGPT2 signaling activated after estrogen depletion paradoxically triggers ER+ tumor cell awakening from dormancy in their BM niche, partly indirectly via endothelial Tie2 receptor and partly directly via tumor cell surface integrin $\beta 1$.
\end{abstract}

Key Words
- breast
- bone
- metastasis
- endocrine therapy
resistance
- cell signaling

Endocrine-Related Cancer (2016) 23, 609-623

\section{Introduction}

Tumor cells frequently escape the primary site and disseminate into multiple distant organs such as bone marrow (BM) (Aguirre-Ghiso 2007). The cells may remain there in a dormant, growth-arrested state for a long time. Disseminated dormant tumor cells can threaten patients' survival, since the tumor cells are resistant to standard adjuvant therapies, can evade current monitoring protocols (Braun et al. 2000) and eventually be reactivated to form metastatic tumors (Janni et al. 2005, Janni et al. 2011). Recurrence after long period of dormancy is especially common in estrogen receptor-positive (ER+) breast cancer (Han et al. 2016, 
Zhang et al. 2013). While estrogen receptor-negative (ER-) cancer rarely recurs after 5 years, ER+ cancer often recurs even decades after otherwise successful primary tumor treatment. Understanding the molecular mechanisms of tumor dormancy and reactivation can facilitate the development of therapeutic strategies against metastatic recurrence (Giancotti 2013), comprising most of the ER+ breast cancer patient mortality (Goss \& Chambers 2010).

Tumor cell dormancy seems to be regulated by a special environment, called a niche, which exists in lymph node, lung or BM (Aguirre-Ghiso 2007). Since niche exists only sparsely and dormant tumor cells are even sparser, human or animal study of tumor cell dormancy in niche is a technical challenge itself. In vitro models of tumor dormancy, therefore, have crucial importance in this field (Barkan \& Green 2011). For instance, the $\mathrm{BM}$ niche contains many types of stromal cells, including mesenchymal stem cells (MSCs), osteoblasts, pericytes, fibroblasts and endothelial cells (ECs) (Mendez-Ferrer et al. 2010, Kunisaki et al. 2013). Among the cellular components, the role of EC is an emerging topic of importance (Ghajar 2015). Ghajar and coworkers (2013) found out that endothelial components regulate breast tumor cell dormancy in lung and BM perivascular niches by utilizing both in vitro co-culture models of BM niche and in vivo models. Similarly, Marlow and coworkers (2013) developed a three-dimensional co-culture model of BM niche by mixing MSCs, osteoblasts and ECs, which successfully reproduced dormancy of bone metastatic breast cancer in human.

In general, ER+ tumor cells need estrogen for survival and proliferation. However, many metastatic events of ER+ breast cancer come after years of adjuvant antiestrogen therapy or after menopause when systemic estrogen levels become extremely low (Zhang et al. 2013). Furthermore, it is argued that estrogen depletion may promote, paradoxically, breast cancer metastasis. For example, Ottewell and coworkers (2014) reported that ER- breast cancer bone metastasis in animal model did not decrease but increased after ovariectomy, especially via osteoclast activation. Similarly, McBryan and coworkers (2015) reported that antiestrogen treatment using tamoxifen promoted particularly metastatic recurrence of endocrineresistant ER+ breast cancer. Both results imply that estrogen deficiency can remodel the microenvironment of secondary organs, which may also support survival and metastasis of endocrine-sensitive ER+ tumor cells.
Angiopoietin-2 (ANGPT2) may be the switch underling ER+ breast cancer relapse after estrogen depletion. ANGPT2 is expressed by endothelium and acts as an autocrine or paracrine antagonist of ANGPT1 (Augustin et al. 2009). It has been gaining attention as a promising target in cancer therapy, and specific inhibitors are now available (Saharinen et al. 2011, Eroglu et al. 2013). In primary organ, ANGPT2 directly stimulates tumor angiogenesis (Eroglu et al. 2013). In metastatic sites, ANGPT2 loosens the endothelial cell-cell junction, which enhances extravasation of disseminated tumor cells (Schulz et al. 2011, Holopainen et al. 2012, Avraham et al. 2014). Yet, its role after tumor cell extravasation, especially on tumor cell dormancy and reawakening, has not yet been explored. Since estrogen regulates ANGPT1, 2 expressions in other tissues (Ardelt et al. 2005, Matsuoka-Sakata et al. 2006, Bonagura et al . 2010, Harfouche et al. 2011), we hypothesized that estrogen deficiency may modulate ANGPT2 signaling in the BM niche, triggering ER+ tumor cell awakening from dormancy. Herein, we demonstrate that estrogendeficient BM niche overexpresses angiopoietin-2, which negates ER+ tumor cell dormancy and eventually promotes estrogen-independent tumor growth.

\section{Materials and methods}

\section{Cell lines and culture conditions}

Breast cancer cell lines MCF7, BT474, MDA-MB-361 and MDA-MB-231 were obtained from the American Tissue Culture Collection (ATCC) and grown in complete RPMI-1640 medium (Gibco) supplemented with 10\% fetal bovine serum (FBS; Gibco), $100 \mathrm{unit} / \mathrm{mL}$ penicillin and $100 \mu \mathrm{g} / \mathrm{mL}$ streptomycin (passage number ranged from 9 to 15). Above cell lines were authenticated by standard short tandem repeat (STR) DNA typing methodology before being purchased from the ATCC. Primary human umbilical vein endothelial cells (ECs) at second passage were obtained commercially (C-12203, lot \#3070401, PromoCell GmbH, Heidelberg, Germany) and grown in endothelial cell growth medium 2 (EGM2; PromoCell, Heidelberg, Germany) in a humidified chamber $\left(37^{\circ} \mathrm{C}, 5 \% \mathrm{CO}_{2}\right)$. Primary human bone marrow mesenchymal stem cells (BM MSCs) at second passage were obtained from Yonsei Cell Therapy Center (lot \#B090429-04; \#B110124-07, Seoul, Korea). BM MSCs were maintained in low glucose Dulbecco's Modified Eagle Medium (DMEM; Gibco) supplemented with 10\% FBS,

Published by Bioscientifica Ltd. 
$100 \mathrm{unit} / \mathrm{mL}$ penicillin and $100 \mu \mathrm{g} / \mathrm{mL}$ streptomycin. Endothelial cells (ECs) and BM MSCs isolated between passages 5 and 10 were used in these experiments.

\section{Generation of tumor cells expressing fluorescent tags}

Tumor cell lines were tagged with red fluorescent protein (RFP) or enhanced green fluorescent protein (GFP) using a lentiviral transduction system. Briefly, pLenti CMV/TO Puro empty vector was obtained from Addgene (Addgene plasmid 17482; Cambridge, MA, USA) 49. RFP and GFP (sequences obtained from GenBank) were cloned into pLenti $\mathrm{CMV} / \mathrm{TO}$ Puro empty vector. Lentivirus was generated by co-transfection of packaging vectors pMDLg/pRRE, pMD2G, pRSV-Rev (Addgene plasmids 12251, 12253, and 12259) and pLenti CMV/TO Puro-RFP or pLenti CMV/TO Puro-GFP into 293T cells with $2.5 \mathrm{M}$ calcium chloride. RFP- or GFP-expressing tumor cells lines were generated by lentiviral infection and selection for 1 week in $1 \mu \mathrm{g} / \mathrm{mL}$ puromycin.

\section{In vitro model of bone marrow niche}

MSCs and ECs were co-cultured in EGM2 for 5-7 days to reach confluence. For three-dimensional (3D) culture, growth-factor-reduced, phenol-red-free Matrigel matrix (Corning) was used to coat the vessels before cell seeding. To discriminate ECs from MSCs, ECs were stained with carboxyfluorescein succinimidyl ester (CFSE, Life Technologies) before co-culture. Cell numbers and culture volumes were as follows: $5 \times 10^{3}$ MSCs, $2 \times 10^{3}$ ECs in microfluidic plates. $5 \times 10^{4}$ MSCs, $2 \times 10^{4}$ ECs and $200 \mu \mathrm{L}$ EGM2 per well in 96-well microplates; $2 \times 10^{5}$ MSCs, $5 \times 10^{4}$ ECs and $2 \mathrm{~mL}$ EGM2 per well in 6-well microplates; and $2 \times 10^{6}$ MSCs, $5 \times 10^{5}$ ECs and $10 \mathrm{~mL}$ EGM2 in $100 \mathrm{~mm}$ dishes.

\section{Monitoring tumor cell proliferation using continuous fluidic cell culture system}

A microfluidic live-cell imaging platform (CellASIC ONIX Microfluidic Platform, EMD Millipore) was utilized to supply nutrients and oxygen and remove wastes with minimal stress to cells. Cell culture was performed according to the manufacturer's instructions. Briefly, $10 \mu \mathrm{L}$ MSC and EC cell suspensions $\left(1 \times 10^{6}\right.$ total cells $/ \mathrm{mL}$ ) was loaded onto a microfluidic culture plate (M04S, EMD Millipore), which has a compatible culture volume as that of 384-well microplate. The plate was attached to the platform controlling perfusion flow, temperature and gas composition. An inverted fluorescence microscope was used for live-cell imaging with the $40 \times$ objective. The cells were incubated (EGM2, $37^{\circ} \mathrm{C}, 5 \% \mathrm{CO}_{2}$ ) for $5-7$ days until reaching confluence. Then, fluorescence-expressing tumor cells were seeded sparsely onto BM niche culture plates. Tumor cell seeding numbers were as follows: $0.5 \times 10^{2}$ cells per well in microfluidic plate, $2 \times 10^{2}$ cells per well in 96-well microplates, $4 \times 10^{3}$ cells per well in 6-well microplates and $2 \times 10^{4}$ MCF7 in $100 \mathrm{~mm}$ dishes. For microfluidic culture, tumor cell proliferation was monitored by capturing time-lapse images of the cells using a fluorescence microscope (Nikon Eclipse Ti, Nikon Instruments). For conventional culture, a fluorescence microplate reader (Varioskan Flash Multimode Reader, Thermo Scientific) was used to measure cell fluorescence every $24 \mathrm{~h}$ after cell seeding. Fluorescence intensity was measured using bottom optic readings. Excitation/ emission wavelengths were $553 / 574 \mathrm{~nm}$ for RFP and 488/507 nm for GFP.

To compare proliferative capacities of tumor cells co-cultured with different stromal cell compositions (MSCs, MSCs-ECs or no stromal cells as a control), all cells were harvested by trypsinization after co-culturing for up to 7 days. Fluorescence-positive cells were sorted and collected using fluorescence-activated cell sorting (FACS) (FACSAria cell sorter; BD Bioscience, San Jose, CA, USA), and seeded onto new empty plates $\left(2 \times 10^{3}\right.$ cells per well in 96-well microplates). Cell proliferative capacity was assessed again by measuring fluorescence intensity every $24 \mathrm{~h}$.

\section{Flow cytometry to detect ERK1/2 and p38 activities}

GFP-expressing tumor cells were cultured alone or with MSCs and/or ECs in $100 \mathrm{~mm}$ dishes for 7 days. Cells were trypsinized, washed with phosphate-buffered saline (PBS) and fixed with 4\% paraformaldehyde for $10 \mathrm{~min}$. The fixed cells were chilled on ice and permeabilized with $90 \%$ methanol for $30 \mathrm{~min}$. Then, $1 \times 10^{6}$ cells per experimental condition were aliquoted, washed and resuspended in $100 \mu \mathrm{L}$ fluorochrome-conjugated primary antibodies against p38, phosphorylated p38 (Santa Cruz Biotechnology), ERK1/2 and phosphorylated ERK1/2 (Cell Signaling Technology) at the manufacturer's recommended concentrations, and incubated for $1 \mathrm{~h}$. For isotype control, fluorochrome-conjugated rabbit IgG was used at the same concentration. Cells were washed, resuspended in PBS, sorted for GFP fluorescence and analyzed using the FACSAria cell sorter.

Published by Bioscientifica Ltd 


\section{Estrogen depletion and supplement in culture}

FBS stripped with charcoal-dextran was purchased from Gemini Bio-Products (Gemini Bio-Products, West Sacramento, CA, USA). To evaluate the effect of estrogen depletion on BM niche, MSCs and/or ECs were cultured in phenol-red-free RPMI 1640 containing $10 \%$ charcoal-stripped FBS supplemented with or without $200 \mathrm{pg} / \mathrm{mL} 17 \beta$-estradiol (E2758, Sigma-Aldrich). Because the charcoal-stripping process eliminates estrogen and other steroidal hormones essential for primary EC survival, hydrocortisone $(0.2 \mu \mathrm{g} / \mathrm{mL})$ was added to the final medium. To supplement estrogen, 17- $\beta$ estradiol (Sigma-Aldrich) was added.

\section{Modulation of receptor-ligand interaction}

To evaluate the effect of angiopietin-1, 2 on tumor cell proliferation, cultures were treated with $0,50,100$ or $500 \mathrm{ng} / \mathrm{mL}$ recombinant human angiopoietin-1 and recombinant human angiopoeitin-2 (R\&D Systems). To block angiopoietin-1 and Tie 2 receptor interaction, cultures were treated with $10 \mu \mathrm{g} / \mathrm{mL}$ of human Tie2 affinity-purified polyclonal antibody (R\&D Systems). To knockdown angiopoietin-2 in culture, short-inhibiting RNAs (siRNAs) were used. Three different siRNAs that are known to block specifically angiopoietin-2 mRNA were generated:

\section{\#1 5'-GGAAGAGCAUGGACAGCAUAGGA-3' (D'Souza et al. 2012) \\ \#2 5'-AGAACCAGACGGCUGUGAUGAUAGAAA-3' (Daly et al. 2006) \\ \#3 5'-CCAGACGGCUGUGAUGAUA-3' (Mangan etal. 2007)}

Negative and positive control siRNAs were obtained from GenePharma (Suzhou, China). Cells were prepared and cultured as described above and siRNAs were transfected using transfection reagent G-Fectin (Genolution Pharmaceuticals. Seoul, Korea) according to the manufacturer's protocol. Briefly, $1 \mu \mathrm{L}$ G-Fectin and 5 pmol siRNA were incubated in $50 \mu \mathrm{L}$ PBS at room temperature for $10 \mathrm{~min}$, and added to cell culture plate (24-well). Culture medium was replaced $8 \mathrm{~h}$ after transfection to minimize cytotoxicity. Angiopoietin-2 knockdown was assessed by PCR using total RNA extracted from cells $48 \mathrm{~h}$ post-transfection.

To knockdown ITGB1, we used the SureSilencing shRNA plasmid for human ITGB1 (KH00650G for the GFP) and a scrambled sequence negative control plasmid (SABiosciences, Frederick, VA, USA), as described previously (Choi et al. 2012). The shRNA target sequence for ITGB1 was as follows: 5'-TGT GCT CAG TCT TAC TAA TAA-3'. The cells were seeded and transfected using the Attractene Transfection Reagent (Qiagen) according to the manufacturer's protocol.

\section{RNA extraction and reverse transcription polymerase chain reaction (RT-PCR)}

As described previously (Kang et al. 2013), total RNA was isolated from cells using an RNeasy Protect Mini Kit (Qiagen) according to the manufacturer's protocol. The Super-Script III Reverse Transcriptase kit (Invitrogen) was used to synthesize cDNA. Polymerase chain reactions (PCRs) were performed with HotStarTaq DNA polymerase (Qiagen) and the following conditions: denaturation at $95^{\circ} \mathrm{C}$ for $15 \mathrm{~min}$, and 28 cycles of $95^{\circ} \mathrm{C}$ for $40 \mathrm{~s}, 52^{\circ} \mathrm{C}$ for $1 \mathrm{~min}$ and $72^{\circ} \mathrm{C}$ for $1 \mathrm{~min}$, with a final extension for $10 \mathrm{~min}$ at $72^{\circ} \mathrm{C}$. Expression levels of GAPDH were assessed as an internal control in all reactions. The following primers were used for PCR: forward primer for angiopoietin-1 5'-GAAGGGAACCGAGCCTATTC-3', reverse primer 5'-GGGCACATTTGCACATACAG-3'; forward primer for angiopoietin-2 5'-TGGGATTTGGTAACCCTTCA-3', reverse primer 5'-GGTTGGCTGATGCTGCTTAT-3' .

\section{Western blotting assay}

As described previously (Kang et al. 2013), cells were trypsinized and lysed by Pro-Prep protein extraction kit (iNtRON Biotechnology, Seongnam, Korea). Equal amounts of protein extracts $(20 \mu \mathrm{g})$ were separated by sodium dodecyl sulfate-polyacrylamide gel electrophoresis and transferred to a nitrocellulose membrane (Invitrogen). Blots were blocked with 5\% nonfat dry milk at room temperature. The blots were incubated with antibodies specific for angiopoietin-1 (ab183701, Abcam), angiopoietin-2 (ab155106, Abcam), phosphorylated Tie2 (Tyr992, \#4221, Cell Signaling Technology), Tie2 (sc-9026), thrombospondin-1 (sc-59886) and $\beta$-actin (Santa Cruz Biotechnology) at specific dilution, followed by incubation with peroxidase-labeled secondary antibodies. Immunoreactive proteins were visualized using an enhanced chemiluminescence detection kit (Santa Cruz Biotechnology). Blot images were captured using ImageQuant LAS 4000 biomolecular imager (GE Healthcare Life Sciences). Blot intensities were quantified using Image $1.48 \mathrm{v}$ software (http://imagej. nih.gov/ij) (Schneider et al. 2012).

Published by Bioscientifica Ltd. 


\section{Graphics and statistical analysis}

For survival analysis of human patients, statistical significance was determined using Kaplan-Meier method and log-rank test. For in vitro experiments, statistical significance was determined using Student's $t$-test and ANOVA. Results were considered to be significant at $P<0.05$. Statistical analyses were computed with IBM SPSS Statistics 20 software. All graphical presentations were created using GraphPad Prism 6 software.

\section{Results}

\section{Angiopoietin-1, 2 regulate ER+ tumor cell dormancy in BM endothelial niche}

Angiopoietin-1/Tie2 signaling is active in the BM niche, mainly participating in hematopoietic stem cell quiescence (Arai et al. 2004). If angiopoietin signaling does have a role in ER+ tumor metastatic recurrence, it is probably working also in the BM niche where disseminated tumor cells are most likely to reside. To test the impact of angiopoietin signaling on ER+ breast tumor dormancy in BM niche, we utilized existing in vitro models (Barkan \& Green 2011, Ghajar et al. 2013, Marlow et al. 2013). Briefly, to create a microenvironment similar to BM niche, human BM-derived MSCs and/or ECs were co-seeded onto extracellular matrix-coated microplates (Fig. 1A). These were designated as 'mesenchymal niche' or 'endothelial niche', based on the presence of ECs. Without ECs, BM-derived stromal cells (mesenchymal niche) generally support breast tumor cell growth, whereas EC-contained niche (endothelial niche) inhibits tumor cell growth (Marlow et al. 2013). To optimize the system for our studies, a few modifications have been introduced: a commercial continuous fluidic cell culture system was used to supply nutrients and oxygen and remove wastes with minimal stress to cells during long-term culture; charcoal-stripping fetal bovine serum (FBS) was used to eliminate serum-derived estrogen.

The niches were incubated until their cells reaching confluence in medium containing 10\% charcoal-stripped FBS supplemented with estradiol $\left(\mathrm{E}_{2}\right) 200 \mathrm{pg} / \mathrm{mL}$. Then, fluorescence-expressing ER+ human breast tumor cells were seeded sparsely onto the niche surface. Stromal cells and tumor cell seeding densities were determined by references and our own preliminary studies (Supplementary Fig. 1, see section on supplementary data given at the end of this article). Tumor cell proliferation was monitored by its fluorescence visualization using a microplate reader and a microscope. MCF7 breast tumor cells exhibited significant growth suppressions in endothelial niche compared with those of the mesenchymal niche or cultured alone (Fig. 1B and C). The results were repeated in other ER+ tumor cell lines BT474 and MDA-MB-361 (Supplementary Fig. 2A and B). An ER-negative cell line MDA-MB-231 did not show growth suppression in endothelial niche (compared with those cultured alone), but its proliferation rate in mesenchymal niche was significantly higher than those in endothelial niche or cultured alone (Supplementary Fig. 2C). Mitogen-activated protein (MAP) kinases activity ratio of ERK1/2 and p38 (ERK/p38 ratio) can be used as an indicator of tumor cell dormancy and awakening: proliferative tumor cells exhibit high ERK/p38 ratio, while dormant tumor cells exhibit low ERK/p38 ratio (Sosa et al. 2011). Since both proteins are active in phosphorylated forms, we analyzed their phosphorylation status in MCF7 cells grown in mesenchymal niche and endothelial niche by FACS. Compared with those cultured alone or in mesenchymal niche, tumor cells in endothelial niche exhibited a shift toward low ERK/p38 ratio (Fig. 1D). When the tumor cells cultured in endothelial niche were harvested and reseeded in empty plates, they started replication and generated tumor, implying that their tumorigenic potentials were maintained (Fig. 1E). Growth suppression of tumor cells in our endothelial niche model could be extended up to 3 weeks (Fig. 1F).

Vascular phenotype inside tumor can be switched by modulating angiopoeitin-1/Tie2 signaling (Reiss et al. 2009). We tested the effect of angiopoietin-1/Tie2 signaling modulation on tumor cell dormancy in BM endothelial niche. We added human Tie2-receptorspecific blocking antibody $(10 \mu \mathrm{g} / \mathrm{mL})$ to culture medium of endothelial niche. Compared with untreated control, the growth of ER+ tumor cells in endothelial niche significantly increased upon Tie2 blockade (Fig. 2A). In contrast, recombinant human angiopoietin-1 (RhAng1) $500 \mathrm{ng} / \mathrm{mL}$ treatment further suppressed tumor cell proliferation in endothelial niche (Fig. 2A). Again, Tie2 blockade significantly increased tumor cell proliferation in RhAng1-treated endothelial niche. Meanwhile, the growth of tumor cells in mesenchymal niche or those cultured alone were not affected by either Tie2 blockade or RhAng1 (Fig. 2A). Tumor cell proliferation rates in the endothelial niches were correlated with their Tie2 receptor activities and thrombospondin-1 (TSP-1) levels (Fig. 2B). Next, tumor cell's ERK/p38 activity ratio was examined. Upon Tie2 blockade, ERK/p38 high (awaken) MCF7 cell population in endothelial niche increased while ERK/p38 low (dormant) population decreased (Fig. 3B).

Published by Bioscientifica Ltd 
A

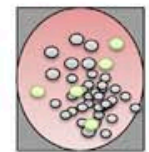

\section{Incubate \\ 5-7 days}

ECM pre-coated dish

+1 - MSCs 0

$+1-$ ECs 0
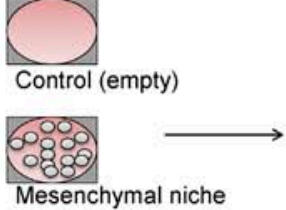

Mesenchymal nich

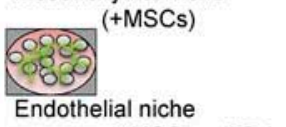

$(+\mathrm{MSCs}+\mathrm{ECs})$

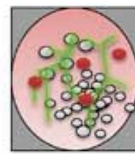

+ RFP-expressing tumor cells *

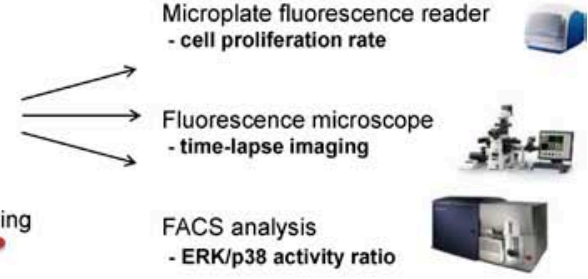

ERK/p38 activity ratio
C

Representative images of MCF $7^{R F P}$ in niche

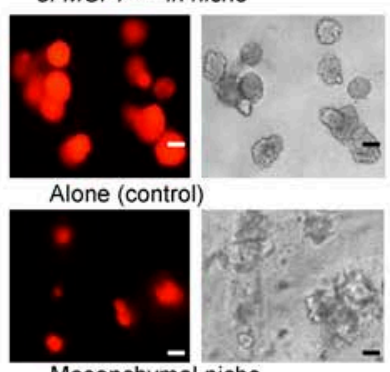

Mesenchymal niche

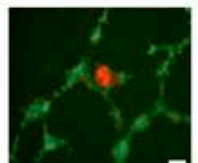

Endothelial niche
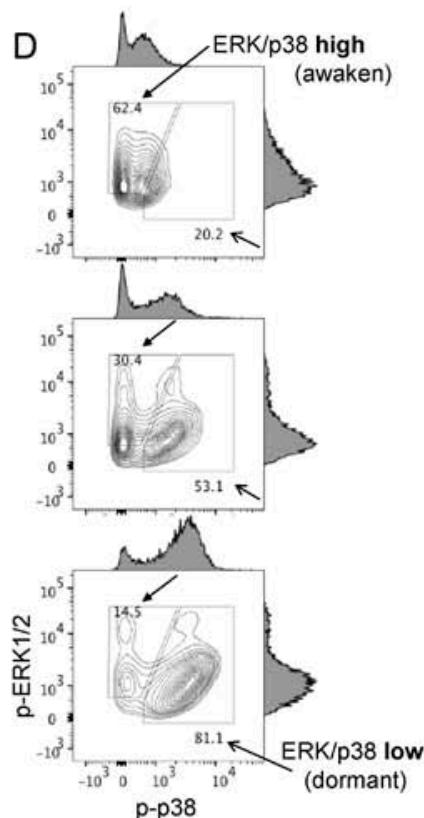

p-p38

F

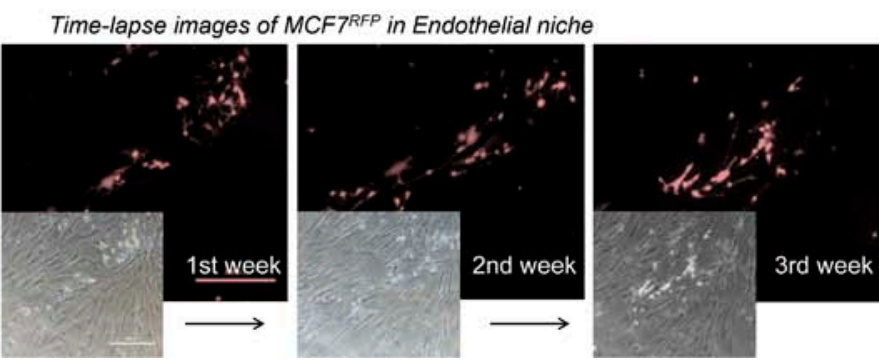

Figure 1

ER+ breast tumor cell MCF7 dormancy in bone marrow endothelial niche models. (A) Experimental scheme. BM MSCs and/or ECs were seeded on 96-well microplates and incubated until reaching confluence. For 3D cultures, Matrigel was coated $\left(150 \mu \mathrm{L} / \mathrm{cm}^{2}\right)$ onto the culture plate. Then, RFP-expressing tumor cells were sparsely seeded ( 200 cells/well) onto the niche cells or empty surfaces (control). Tumor cell proliferations were assessed by fluorescence intensity reader and microscope, and fluorescence-activated cell sorting (FACS). (B) Seven-day proliferation rates of MCF7 cells in niches (five sample sets per group; error bars: \pm standard deviation (s.D.) $* P<0.05$ ). (C) Representative images of tumor cells in the niches, captured after 7 days of co-culture (left: fluorescence (red and green); right: bright-field. scale bar $=100 \mu \mathrm{m}$ ). For visualization, ECs were prestained with CFSE (green). (D) FACS analysis of ERK1/2 and p38 MAR kinase activities of MCF7 tumor cells in niche. Upper: tumor cell alone; middle: tumor cell in mesenchymal niche; lower: tumor cell in endothelial niche. Blank arrows: ERK/p38 ratio-low (dormant) population; filled arrows: ERK/p38 ratio-high (awaken) population. (E) Replicative potentials of dormant MCF7 tumor cells. Tumor cells were harvested from niche and replated in 96-well microplates ( 500 cells/well). Box-plots represent fluorescence intensity fold-changes for 7 days (five samples per condition. horizontal bar = mean). (F) Time-lapse images of tumor cell dormancy in niche. MCF7RFP cells were cultured in endothelial niche for up to 21 days (fresh medium replaced every $48 \mathrm{~h}$ ). Cells remain at almost the same number during the period. (Upper: fluorescence (red); lower: bright-field. scale bar $=500 \mu \mathrm{m}$ ). BM MSC, bone marrow-derived mesenchymal stem cell; EC, endothelial cell; ER, estrogen receptor; MAP, Mitogen-activated protein; p-ERK1/2, phosphorylated ERK1/2; p-p38, phosphorylated p38; RFP, red fluorescence protein. A full colour version of this figure is available at http://dx.doi.org/10.1530/ERC-16-0086. 
In contrast, RhAng1 further increased dormant tumor cell population in endothelial niche (Fig. 2B). Combination of RhAng1 treatment and Tie2 blockade recovered the activity ratio of ERK/p38 MAP kinases in similar degree to those of untreated control (Fig. 2B). We also tested the effect of recombinant human angiopoietin-2 (RhAng2), a competitive antagonist of angiopoeitin-1. Similarly, RhAng2 500 ng/mL treatment promoted MCF7, BT474 and MDA-MB-361 cell proliferations only in endothelial niche, not in mesenchymal niche or in empty plate (tumor cell alone) (Supplementary Fig. 3A, B and C).

\section{Estrogen depletion negates ER+ tumor cell dormancy in BM endothelial niche via increased angiopoietin-2 signaling}

To test the effect of estrogen deficiency on ER+ breast tumor dormancy in BM niche, the growth rates and ERK/p38
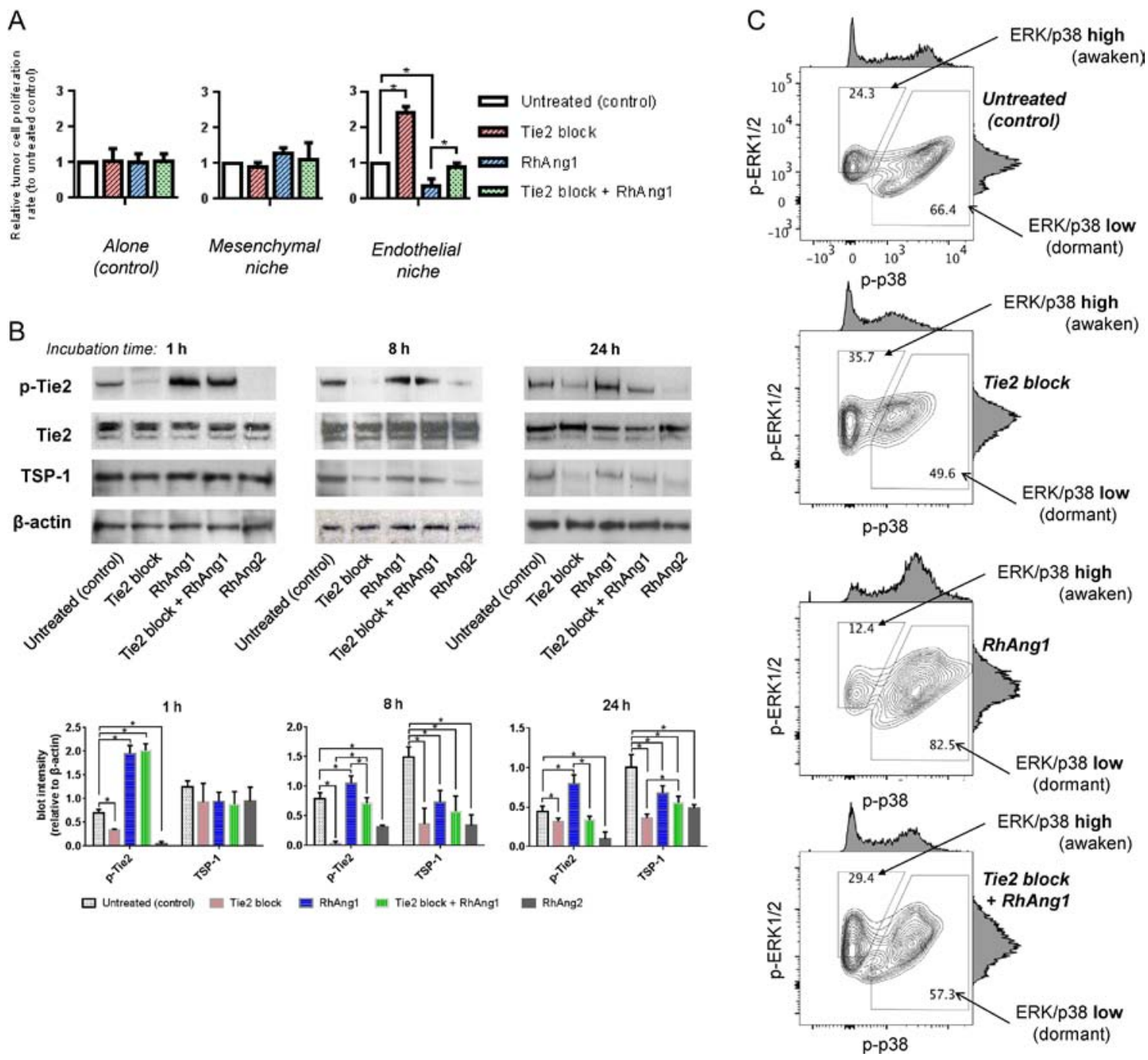

Figure 2

Disruption of endothelial angiopoietin-1/Tie2 signaling elicits awakening of dormant MCF7 tumor cells in endothelial niche. (A, B and C) To modulate endothelial angiopoietin-1/Tie2 signaling in culture, $500 \mathrm{ng} / \mathrm{mL}$ recombinant human angiopoietin-1 (RhAng1) or $10 \mu \mathrm{g} / \mathrm{mL}$ human Tie2 receptor-specific blocking antibody were treated on the niche models. ER+ tumor cell dormancy/awakening states in the niches were assessed by fluorescence intensity reader and FACS. (A) Relative tumor cell proliferation rates in niches. Cell proliferation rates for 3 days of RhAng1 and/or Tie2 blockade were analyzed. Data are presented as mean signaling intensity changes, relative to untreated control ( $n=3$ per condition. Error bar: \pm s.D. $\left.{ }^{*} P<0.05\right)$. (B) Endothelial niche Tie2 receptor phosphorylation and thrombospondin-1 (TSP-1) level changes upon Tie2 block, RhAng1, Tie2 block+RhAng1 or RhAng2 500 ng/mL. Above: representative lot images. Below: Blot quantification. Normalized to $\beta$-actin. Error bar: s.D. Cells were harvested after 1, 8 or $24 \mathrm{~h}$ of incubation. Experiments were done triplicated. (C) ERK1/2 and p38 MAR kinase activities of tumor cells in RhAng1 and/or Tie2 blocking antibody-treated niches. Filled arrows: ERK/p38 ratio-high population. Blank arrows: ERK/p38 ratio-low population. Black $=$ untreated; red $=$ Tie2 blocked; blue $=$ RhAng1-treated; green =Tie2 blocked \& RhAng1-treated endothelial niches. A full colour version of this figure is available at http://dx.doi.org/10.1530/ERC-16-0086. 
activity ratio of breast tumor cells in $\mathrm{E}_{2}$-supplemented and unsupplemented niches were compared (Fig. 3A). Three ER+ breast cancer cell lines (MCF7, BT474 and MDA-MB-361) and one ER- cell line (MDA-MB-231) were used. MCF7 represents luminal A (ER+, PR+, HER2-), which is totally dependent on estrogen to grow in culture. BT474 represents luminal B (mild ER+, PR+, strong HER2+), MDA-MB-361 also represents luminal B $(\mathrm{ER}+, \mathrm{PR}+$, strong HER2+), both of which are amenable to antiestrogen hormone therapy. MDA-MB-231 represents basal-like subtype (ER-, PR-, HER2-) and is independent of estrogen for growth. When cultured alone, ER+ tumor

A

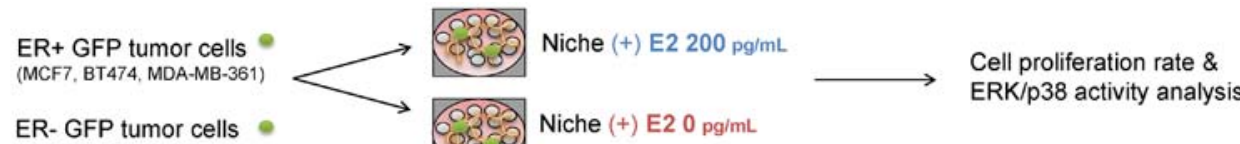

B (MDA-MB-231)

Mesenchymal niche

Endothelial niche
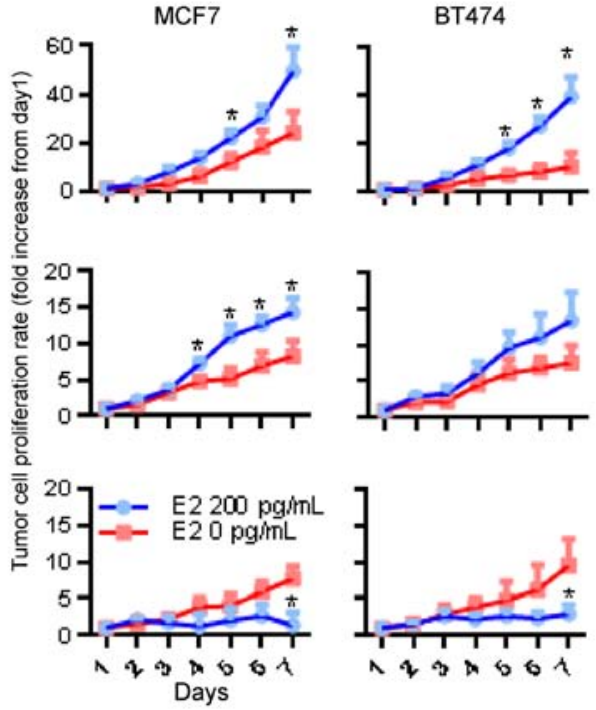

MDA-MB-361
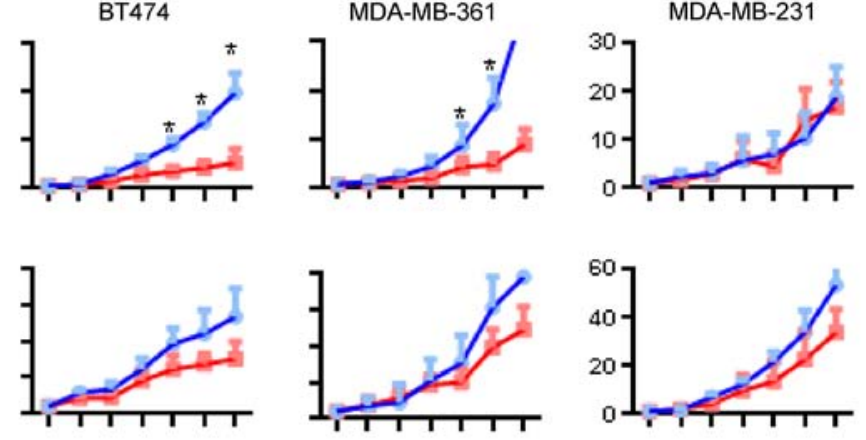

C
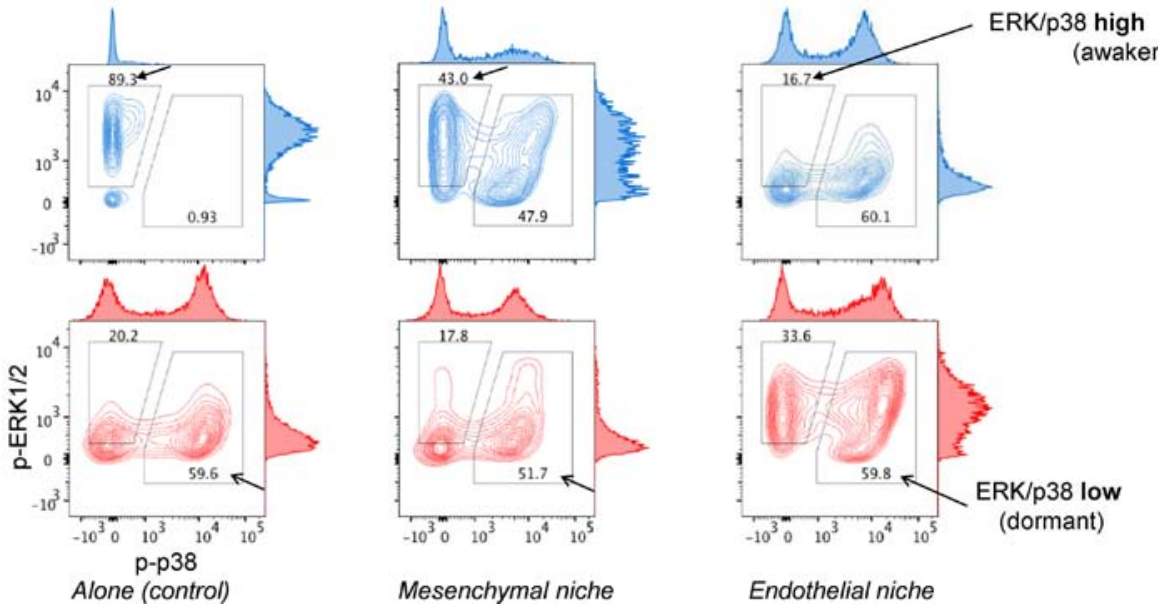

Endothelial niche

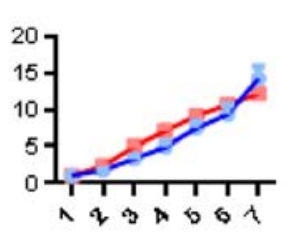

$(-) E 2$

$(+) E 2$

(c)

$(-1)$
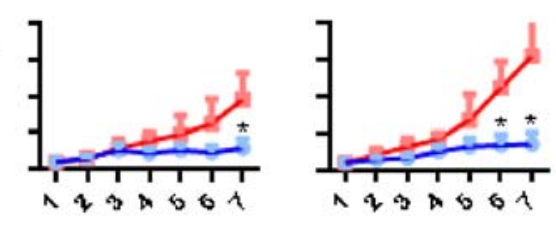

Figure 3

Increased ER+ tumor cell proliferation after estrogen depletion in bone marrow endothelial niche. (A) Experimental scheme. BM niche models were generated by co-culturing BM MSCs and/or ECs on ECM-coated microplates. GFP-expressing tumor cells were sparsely seeded (200 cells/well) onto the niche cells or empty surfaces (control). Tumor cell proliferations were compared in niches cultured using estrogen-supplemented $(200 \mathrm{pg} / \mathrm{mL}$ ) or un-supplemented (depleted) media. (B) Seven-day proliferation rates of tumor cells in niches. From left to right: ER+ MCF7, ER+ BT474, ER+ MDA-MB-361 and ER-MDA-MB-231. (Five sample sets per group; error bars: \pm s.D. ${ }^{*} P<0.05$ ). (C) FACS analysis of ERK1/2 and p38 MAR kinase activities of MCF7 tumor cells in estrogen-supplemented (blue) and estrogen-depleted (red) niches. Filled arrows: ERK/p38 ratio-high population. Blank arrows: ERK/p38 ratio-low population. A full colour version of this figure is available at http://dx.doi.org/10.1530/ERC-16-0086. 
cells grew significantly slower in absence of $E_{2}$ than in presence of E2 (Fig. 3B), implying that estrogen promotes their growths. Similar growth trends were noted in mesenchymal niche too (Fig. 3B). In endothelial niche, contrastingly, ER+ tumor cells grew significantly faster in absence of $E_{2}$ than in presence of $E_{2}$ (Fig. 3B). Such reverse growth trends were not shown in experiments with ER- tumor cells (Fig. 3B). We also tested the effect of 4-hydroxytamoxifen (4-OHT), an active metabolite of tamoxifen (Mandlekar \& Kong 2001), which can effectively suppress ER signaling and ER+ cell growth (Supplementary Fig. 4A and B). Treatment of 4-OHT stimulated MCF7, BT474 and MDA-MB-361 cell growth in endothelial niches, contrary to those cultured alone (Supplementary Fig. 4C and D).

We analyzed ERK/p38 activity ratio in ER+ MCF7 cells cultured alone, in mesenchymal niche or endothelial niche (Fig. 3C). Tumor cells cultured alone or in mesenchymal niche showed decreases in awaken population upon estrogen depletion (ERK/p38 activity ratio-high, 89.3 to $20.2 \%$ and 43.3 to $17.8 \%$, respectively, Fig. 3C). Meanwhile, tumor cells cultured in endothelial niche exhibited increase in awaken subpopulation upon estrogen depletion (ERK/p38 activity ratio-high; 16.7 to $33.6 \%$, Fig. 3C), suggesting disruption of niche-induced tumor cell dormancy.

The results described above suggest that upon estrogen depletion, some tumor dormancy-related factors in endothelial niche changes. We focused on angiopoietin-1 and 2 specifically. In ER+ breast tumor cells, estrogen downregulates angiopoeitin-1 mRNA in an ER-dependent manner (Harfouche et al. 2011). Such regulations may also be active in endothelial cells too. Since the paradoxical growth promoting effect of estrogen depletion was seen

A RT-PCR

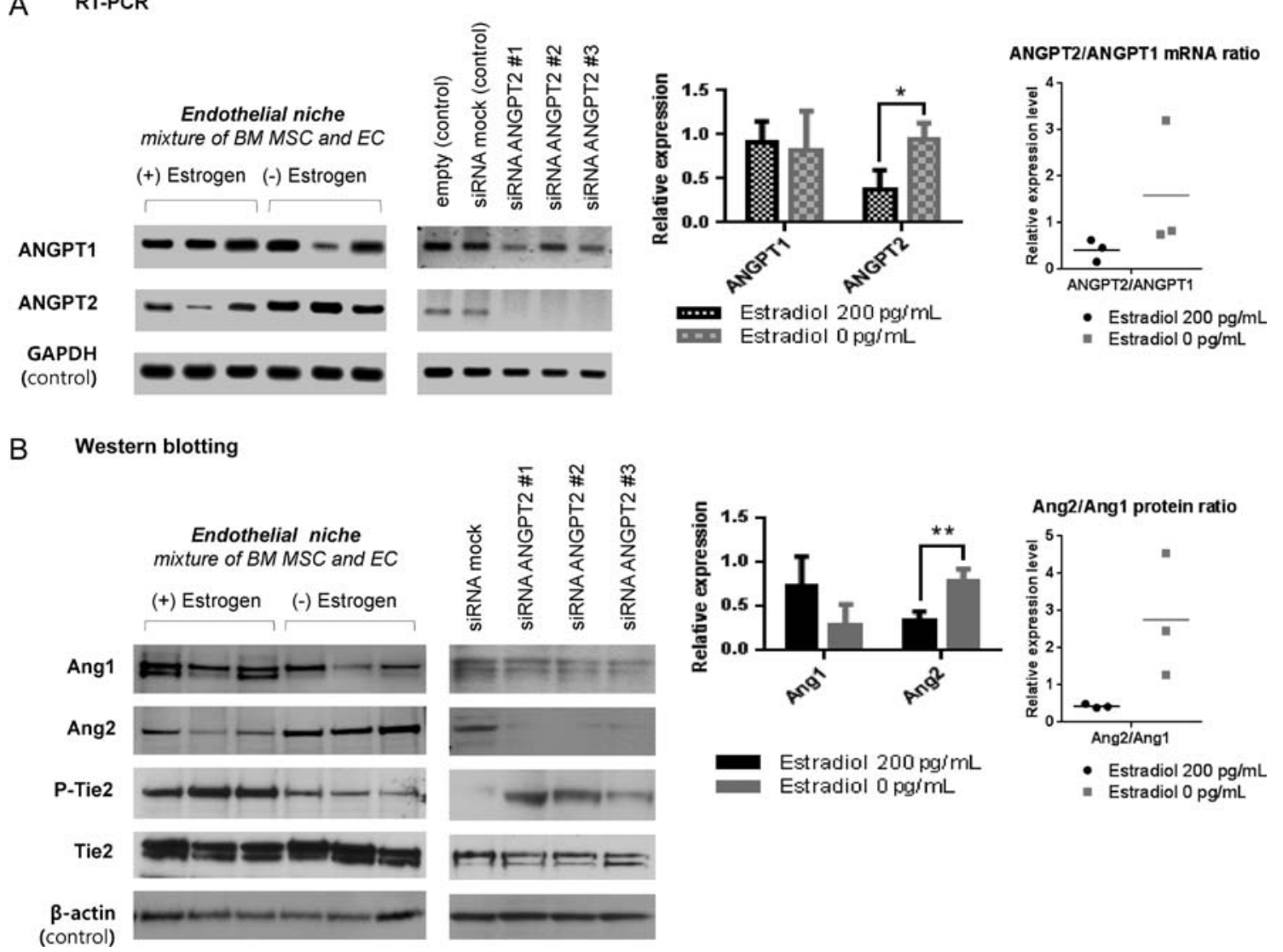

Figure 4

Effect of estrogen depletion on niche endothelial cell angiopoietin-1 and -2 expressions. (A abd B) BM MSC and EC cells were co-cultured with or without estradiol supplementation $(200 \mathrm{pg} / \mathrm{mL}$ ) for 3 days (RT-PCR) or 5 days (Western blotting). Cells were harvested and their expressions of angiopoietin-1, 2 mRNAs (ANGPT1, 2) and proteins (Ang1, 2) were compared by RT PCR (A) and Western blot (B). Specific knockdown of ANGPT2 was performed by transfecting siRNA ANGPT2 \#1, \#2, \#3 in $6 \mathrm{~h}$ after tumor cell seeding. See 'Materials and methods' section for siRNA information. Data in graph (left) are presented as mean blot intensity relative to GAPDH (RT-PCR) or $\beta$-actin (Western blotting). Data in dot graph (right) are presented as Ang2 blot intensity relative to Ang1. All blots were quantified using ImageJ software (IJ 1.46r). (Three sample sets per group. Error bar: S.D. ${ }^{*} P<0.05$.) 
only in endothelial niche, we analyzed the expressions of angiopoietin-1, 2 mRNAs and proteins in endothelial niche cells, in $\mathrm{E}_{2}$-supplemented and unsupplemented (depleted) conditions. In this experiment, tumor cells were not co-cultured. Angiopoietin-1 levels, as both mRNA and protein forms, were not significantly different in $\mathrm{E}_{2}$-supplemented and depleted endothelial niches (Fig. 4A and B). In contrast, angiopoietin-2 mRNA was expressed significantly higher in estrogen-depleted niche than in supplemented niche (Fig. 4A). Protein expression levels exhibited similar trends as well (Fig. 4B). To note, the relative ratio of angiopoietin-2 to angiopoetin-1 level also changed significantly (Fig. 4A and B).

Increased angiopoietin-2 in estrogen-depleted endothelial niche may have shifted tumor cell behavior from dormancy to awakening. This hypothesis was examined by specific knockdown of angiopoietin-2 on niches. Three short-inhibiting RNAs (siRNAs) binding to different angiopoietin-2 mRNA (ANGPT2) sequence (siRNA ANGPT2 \#1, \#2, \#3) significantly attenuated its expressions in endothelial niche (Fig. 4A). Then, tumor cell proliferation rates upon ANGPT2 knockdown in niche were examined. After tumor cells seeded on to estrogen-deficient endothelial niche and mesenchymal niche, siRNAs were treated. After $72 \mathrm{~h}$, all three ER+ tumor cells in estrogen-deficient endothelial niche did not proliferate when ANGPT2 was knocked down (Fig. 5A and B). In contrast, ANGPT2 knockdown had no significant effect on ER+ tumor cell proliferations in estrogen-deficient mesenchymal niche (Fig. 5A and B).

\section{Angiopoietin-2 promotes ER+ tumor cell survival under estrogen depletion via integrin $\beta 1$}

As described above, RhAng2 treatment (500 ng/mL) increased ER+ tumor cell proliferations in otherwise growth-suppressing $\quad \mathrm{E}_{2}$-supplemented endothelial niches (Supplementary Fig. 3A, B and C). RhAng2 had no effect on their proliferations in $\mathrm{E}_{2}$-supplemented mesenchymal niche (Supplementary Fig. 3A, B and C). However, in estrogen-depleted mesenchymal niches, RhAng2 increased tumor cell proliferations, although not always in significant degree and in dose-dependent manner (Supplementary Fig. 2). Since there is no Ang2-responsive ECs in mesenchymal niche, we hypothesized that angiopoietin-2 may act on tumor cells

A

Mesenchymal niche

$(-)$ Estrogen

$(\rightarrow$ Estrogen
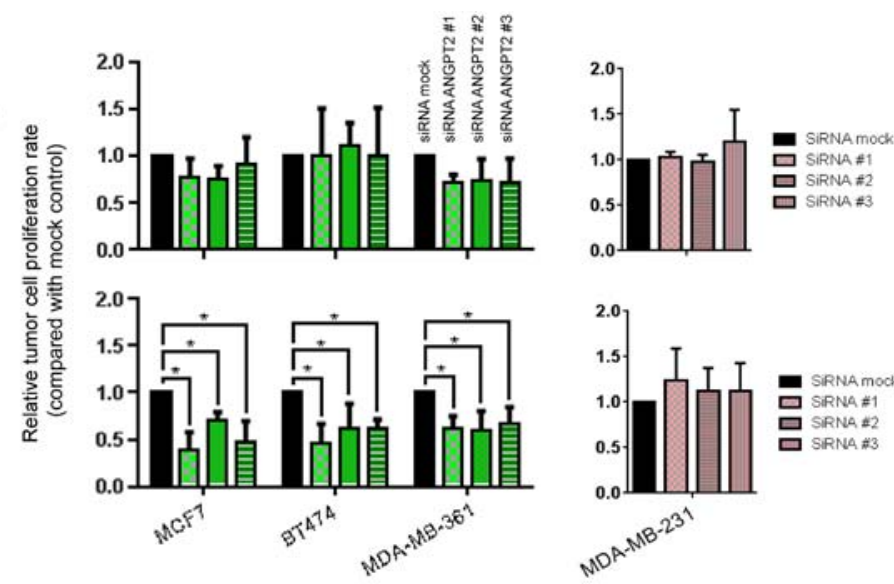

Endothelial niche

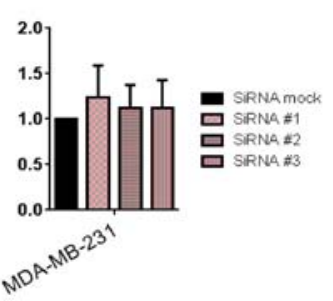

B
Mesenchymal niche
$(-)$ Estrogen
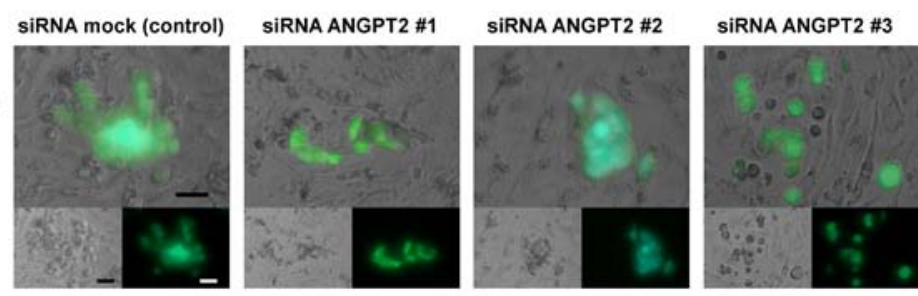

Endothelial niche

(-) Estrogen
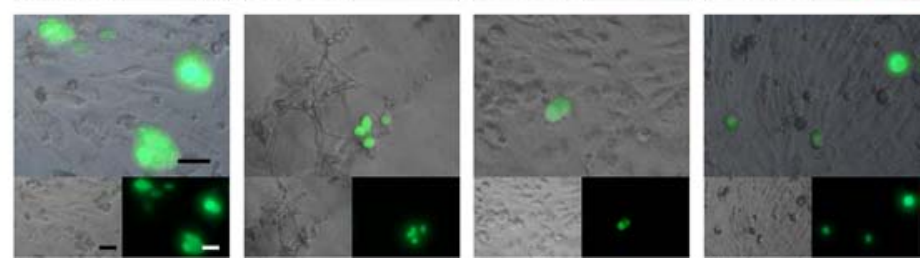

Figure 5

siRNA knockdown of ANGPT2 suppresses

tumor cell proliferation in estrogen-deficient bone marrow endothelial niche. (A and $B$ ) GFP-expressing ER+ tumor cell lines were cultured in niches for 3 days with or without estradiol supplementation ( $200 \mathrm{ng} / \mathrm{mL})$. Specific knockdown of ANGPT2 mRNA in niche was performed by transfecting siRNA \#1, \#2 or \#3 in $6 \mathrm{~h}$ after tumor cell seeding. (A) Relative tumor cell proliferation rates in niches. Cell proliferation rates for 3 days following siRNA transfection were analyzed using fluorescence intensity reader. Data are presented as mean signaling intensity change from day 0 to day 3 relative to siRNA mock control (three sample sets per group; error bar: \pm S.D. ${ }^{*} P<0.05$, by Student's $t$-test). (B) Representative images of mesenchymal niches and endothelial niches treated with siRNAs. Images were captured by fluorescence microscope after 3 days of co-culture (Upper: merged; left lower: bright-field; right lower: fluorescence (green). Scale bar $=50 \mu \mathrm{m}$ ). A full colour version of this figure is available at http://dx.doi.org/ 10.1530/ERC-16-0086. 
directly. Interestingly, Imanishi and coworkers (2007, 2011) reported that angiopoeitin- 2 acts directly on ER+ tumor cells via ITGB1 and promoted their initial survival and metastatic growth at lung. Encouraged by the previous reports, we evaluated the effect of RhAng2 on $\mathrm{ER}+$ tumor cell proliferation under estrogen deficiency. Tumor cells were cultured for 3 days in $\mathrm{E}_{2}$-supplemented or unsupplemented growth media containing varying concentrations of RhAng2 (0, 50, 100, $500 \mathrm{ng} / \mathrm{mL}$, Fig. 6A). In presence of $E_{2}$, RhAng2 had no effect on ER+ and ER- tumor cell proliferations (Fig. 6B). In absence of $\mathrm{E}_{2}$, however, RhAng2 promoted $\mathrm{ER}+$ tumor cell proliferations in dose-dependent manner (Fig. 6C). ER- tumor cell proliferation was not affected by RhAng2 (Fig. 6C). To find-out whether this was dependent on tumor cell ITGB1, we performed ITGB1 knockdown using shRNAs (Supplementary Fig. 6). ITGB1 knockdown itself had no effect on tumor cell growth under estrogen deficiency (Supplementary Fig. 6D). In contrast, ITGB1 knockdown completely negated RhAng2's proliferative effect under estrogen depletion (Fig. 6E).

\section{Angiopoietin-1, 2 expressions correlate with ER+ breast cancer metastatic recurrences following antiestrogen endocrine therapy}

Angiopoietin-2 overexpression in breast cancer is known to correlate with poor patient survival (Sfiligoi et al. 2003). According to our experimental data, its expression would be particularly associated with metastatic recurrence of ER+ subtype after adjuvant antiestrogen therapy. To test the hypothesis, we used a published dataset and a web-based program 'KM plotter' (http://kmplot. com) that contain both gene expression and human

A

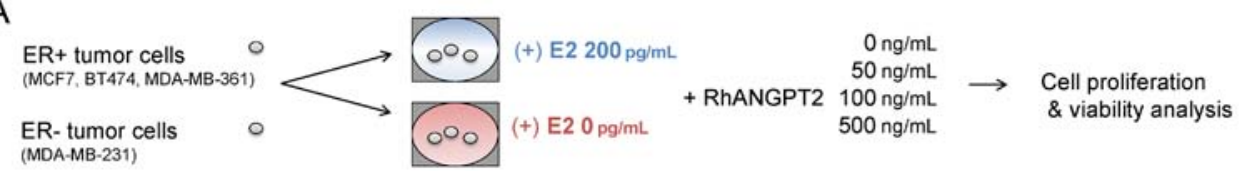

B Estrogen supplement

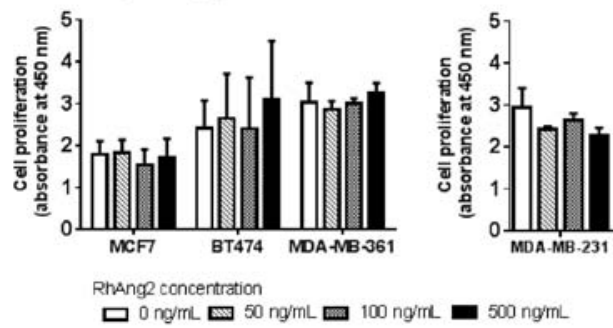

D Estrogen depletion, ITGB1 knockdown

C Estrogen depletion

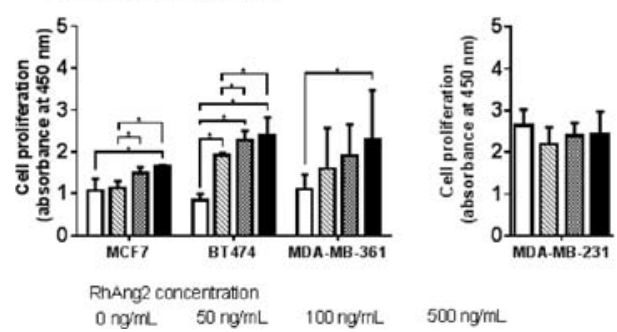

E Estrogen depletion, ITGB1 knockdown
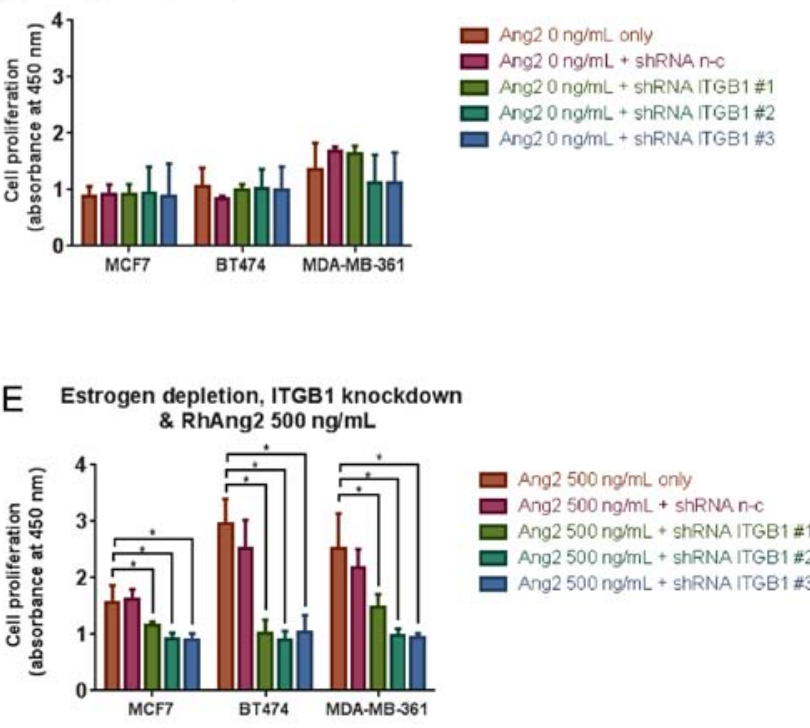

Figure 6

Exogenous angiopoietin-2 promotes ER+ tumor cell survival under estrogen deficiency via cell surface integrin $\beta 1$. (A) Experimental scheme. ER+ breast tumor cell lines MCF7, BT474, MDA-MB-361 and ER-cell line MDA-MB-231 were cultured in 96-well microplates using estradiol-supplemented (200 pg/mL) or un-supplemented (depleted) media. Recombinant human angiopoietin-2 (RhAng2, $0 \mathrm{ng} / \mathrm{mL}, 50 \mathrm{ng} / \mathrm{mL}, 100 \mathrm{ng} / \mathrm{mL}, 500 \mathrm{ng} / \mathrm{mL}$ ) were treated $1 \mathrm{~h}$ after tumor cell seeding. After $48 \mathrm{~h}$, tumor cell proliferation/viability of each condition was assessed using cell counting kit-8 (Dojindo Molecular Technologies, Rockville, MD, USA). (B, C and D) Tumor cell proliferation/viability in presence of RhAng2. (B) Tumor cells cultured in estrogensupplemented media. (C) Tumor cells cultured in estrogen-depleted media. (D) Integrin $\beta 1$ (ITGB1) knockdown tumor cells and untreated cells cultured in estrogen-depleted media. Integrin $\beta 1$ knockdown was performed using short-hairpin RNAs (shRNAs), as described in Supplementary Fig. 6 and previously (Choi et al. 2012). Data presented are mean values of light absorbance rate at $450 \mathrm{~nm}$, representing proliferative activity of each well; error bar: \pm s.D. ${ }^{*} P<0.05$. A full colour version of this figure is available at http://dx.doi.org/10.1530/ERC-16-0086. 
patient survival data (Szasz et al. 2016). Patients were first categorized into those who underwent adjuvant endocrine therapy (including estrogen receptor blocker tamoxifen and aromatase inhibitor, $n=561$ ) or those who did not undergo endocrine therapy $(n=435)$. Then, the patients were further stratified into two groups based on angiopoietin-2 mRNA (ANGPT2) levels in tumor tissue. For those who underwent antiestrogen endocrine therapy, increased ANGPT2 level was associated with a significantly decreased probability of distant metastasis-free survival (DMFS) (Fig. 7A). For those without endocrine therapy, contrastingly, ANGPT2 level was not associated with
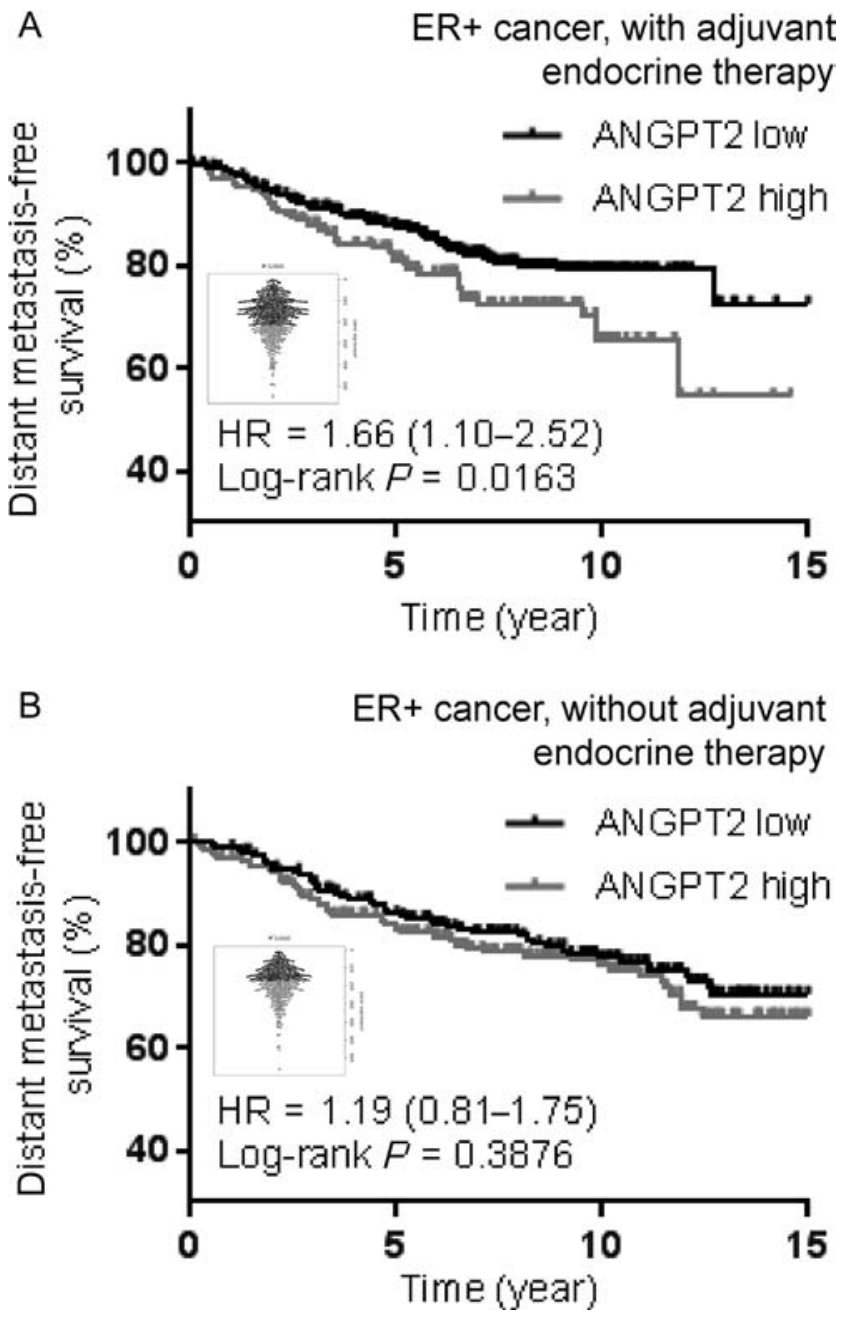

Figure 7

Distant metastasis-free survival of ER+ breast cancer patients, stratified by ANGPT2 expression. Kaplan-Meier analysis comparing distant metastasis-free survival of ER+ breast cancer patients following endocrine therapy $(n=561, \mathrm{~A})$ and those without endocrine therapy $(n=435, \mathrm{~B})$, distinguished by low versus high expressions of ANGPT2. Gene expression data obtained from the open-source KM Plotter (Szasz et al. 2016). Beeswarm graph plots of each RNA prove distribution. ANGPT2, angiopoietin-2 mRNA; ER, estrogen receptor. the probability of DMFS (Fig. 7B). We did not perform a multivariate analysis incorporating known prognostic indicators such as tumor size, grade and number of axillary lymph nodes involved.

\section{Discussion}

The objective of this study was to investigate the effects of estrogen deficiency on BM microenvironment and dormancy of residing ER+ breast tumor cells. We found that prolonged estrogen depletion turned the BM niche in to pro-tumorigenic state, mainly by upregulating angiopoietin-2. Angiopoietin-2 ameliorated the dormancy of ER+ tumor cells in BM endothelial niche and promoted their survival under estrogen deficiency via integrin $\beta 1$ (ITGB1).

Physiologically, angiopoietin-2 destabilizes microvasculature and promotes angiogenesis, via interfering cell surface Tie2 receptor binding to angiopoeitin-1 or activating integrin $\beta 1$ (Augustin et al. 2009, Hakanpaa et al. 2015). Its overexpression has been noted in many types of tumors and linked to poor prognosis (Eroglu et al. 2013). In ovarian cancer, angiopoietin promotes intraperitoneal tumor growth by accumulating cancer-promoting fibroblasts and enhancing tumor angiogenesis (Brunckhorst et al. 2014). In pancreatic cancer, angiopoietin-2 drives lymphatic metastasis (Schulz et al. 2011). In breast cancer, it impairs the blood-brain barrier and support tumor cell colonization in brain (Avraham et al. 2014). In our study, angiopoeitin-2 blocked endothelial Tie2 receptor activity, promoting ER+ tumor cell growth in otherwise growthsuppressing endothelial niche. Thromospondin-1 (TSP-1) is the endothelium-derived growth inhibitory molecule acting on dormant breast tumor cells (Ghajar et al. 2013). Its level in endothelial niche correlated with the Tie2 receptor activity, suggesting it is working in our model too. However, this is in contrast to a previous report that inhibition of Tie2 signaling induces endothelial TSP-1 overexpression (Niu et al. 2004). Our interpretation is that during angiogenesis, endothelial Tie2 activation promotes angiogenesis, lowering TSP-1 production; after vessels formed, endothelial Tie2 activation promotes vessel maturation (Hawighorst et al. 2002), in which TSP-1 production is increased.

Our results underscore the direct action of angiopoietin-2 on ER+ tumor cells too. Unlike Tie2 receptor, which is expressed exclusively in ECs, ITGB1 is expressed in most epithelial tumor cells (Guo \& Giancotti 2004). We showed that angiopoeitin-2 supported

Published by Bioscientifica Ltd 
estrogen-independent tumor cell growth via ITGB1. Interestingly, it has been known that the activation of ITGB1 turns dormant tumor cells into awakening state (White et al. 2004). In addition, angiopoietin- 2 can stimulate tumor cell metastasis to lymph nodes and lung, via activating tumor cell ITGB1 (Imanishi et al. 2007). When those findings combined, it is likely that inactivation of angiopoietin-2 signaling would effectively prevent the metastatic recurrence of breast cancer, particularly of ER+ subtype.

Our study indicates that estrogen regulates angiopoietin-2 expression in BM microenvironment. There appears to be a complex relationship between estrogen level and angiopoietin-1, 2 expressions. Glinskii and coworkers (2007) reported that cessation of ovarian hormone significantly reduced angiopoietin-1 expression in meningeal microvasculature. Similarly, Ardelt and coworkers (2005) reported that estradiol (E2) increased angiopoietin-1 expression in cerebral vascular beds, and Bonagura and coworkers (2010) reported that $\mathrm{E}_{2}$ increased angiopoietin-1 expression in endometrial glandular epithelial cells. In contrast, other reports showed that estrogen administration reduced angiopoietin-1 levels in placenta (Albrecht et al. 2008), in ER+ breast tumor cells (Harfouche et al. 2011) and in some nonreproductive organs (Ye et al. 2002). Furthermore, $\mathrm{E}_{2}$ treatment transiently increased angiopoietin-2 expression in ER+ T47D and ZR75.1 cells, while estrogen depletion also increased angiopoeitin-2 expression in these cells slowly but gradually (Sfiligoi et al. 2003). These discrepancies may reflect differences in experimental conditions and tissue-specific regulatory mechanisms. Nevertheless, all studies suggest that sudden changes in estrogen levels do affect angiopoietin-2 expressions. Therefore, it will be valuable to compare systemic and local angiopoietin-2 levels in pre- and postmenopausal women of breast cancer. Systemic angiopoietin-2 levels may be used as an alarm of disseminated tumor cell awakening too.

The in vitro culture system described here further limits the results of our study. Also, it should be borne in mind that in clinic, macroscopic metastases of ER+ breast cancer may present at a time that there is no apparent change in estrogen levels (Brackstone et al. 2007). Moreover, the experimental condition of rapid estrogen withdrawal is not necessarily same as the long-term low estrogen environment of adjuvant endocrine therapy setting. Therefore, these findings are purely experimental. However, we believe that the experimental design and results are consistent with existing in vivo models and results from human patient studies. We would like to state that any conditional overexpression of angiopoeitin-2, regardless of estrogen level, can provoke metastatic reactivation of solitarily disseminated tumor cells in estrogen-depleted bone microenvironment. Further, preclinical studies using angiopoietin- 2 inhibitors in the premetastatic setting could add significance on our findings.

Treatment strategies for primary breast cancer have been successful. However, for metastatic disease, currently available therapeutic tools are still considered inadequate. ER+ breast cancer is of particular concern because its metastasis often precedes a period of dormancy. Dormant $\mathrm{ER}+$ tumor cells in BM niche are thought to be the seed of metastasis. They are rare and difficult to identify and monitor using currently available methods, and are protected by the microenvironment and their own unique state from conventional cytotoxic chemotherapies. Conversely, dormant tumor cells are not harmful until they become activated and proliferate to form a tumor. Therefore, presence of dormant tumor cells also indicates an opportunity to control metastatic disease even before becoming apparent. Based on current findings, further studies are mandatory to verify the effect of angiopoietin-2 signaling manipulation on late recurrence prevention in women with breast cancer, particularly those under risk of estrogen deficiency.

\section{Supplementary data}

This is linked to the online version of the paper at http://dx.doi.org/10.1530/ ERC-16-0086.

\section{Declaration of interest}

The authors declare that there is no conflict of interest that could be perceived as prejudicing the impartiality of the research reported.

\section{Funding}

This study was supported by the Mid-Career Researcher Program through a National Research Foundation of Korea grant (No. 2016R1A2B4011115; $\mathrm{CNH}$ ) and by a faculty research grant from the Yonsei University College of Medicine (6-2015-0040; CNH). This work was also supported by the Brain Korea 21 PLUS Project for Medical Science, Yonsei University.

\section{Author contribution statement}

$\mathrm{H} \mathrm{H}$ contributed to experimental conception, design, data acquisition, analysis and interpretation, manuscript drafting and revision. B K, J L, $\mathrm{S} \mathrm{K}$ and $\mathrm{J} \mathrm{K}$ contributed to experimental design, data acquisition and interpretation. N C contributed to experimental conception, data interpretation and manuscript revision.

\section{References}

Aguirre-Ghiso JA 2007 Models, mechanisms and clinical evidence for cancer dormancy. Nature Reviews Cancer 7 834-846. (doi:10.1038/ nrc2256)

Published by Bioscientifica Ltd. 
Albrecht ED, Babischkin JS \& Pepe GJ 2008 Regulation of placental villous angiopoietin-1 and -2 expression by estrogen during baboon pregnancy. Molecular Reproduction and Development 75 504-511. (doi:10.1002/mrd.20721)

Arai F, Hirao A, Ohmura M, Sato H, Matsuoka S, Takubo K, Ito K, Koh GY \& Suda T 2004 Tie2/angiopoietin-1 signaling regulates hematopoietic stem cell quiescence in the bone marrow niche. Cell 118 149-161. (doi:10.1016/j.cell.2004.07.004)

Ardelt AA, McCullough LD, Korach KS, Wang MM, Munzenmaier DH \& Hurn PD 2005 Estradiol regulates angiopoietin-1 mRNA expression through estrogen receptor-alpha in a rodent experimental stroke model. Stroke 36 337-341. (doi:10.1161/01.STR.0000153795. 38388.72)

Augustin HG, Koh GY, Thurston G \& Alitalo K 2009 Control of vascular morphogenesis and homeostasis through the angiopoietin-Tie system. Nature Reviews Molecular Cell Biology 10 165-177. (doi:10.1038/nrm2639)

Avraham HK, Jiang S, Fu Y, Nakshatri H, Ovadia H \& Avraham S 2014 Angiopoietin-2 mediates blood-brain barrier impairment and colonization of triple-negative breast cancer cells in brain. Journal of Pathology 232 369-381. (doi:10.1002/path.4304)

Barkan D \& Green JE 2011 An in vitro system to study tumor dormancy and the switch to metastatic growth. Journal of Visualized Experiments 54 2914. (doi:10.3791/2914)

Bonagura TW, Aberdeen GW, Babischkin JS, Koos RD, Pepe GJ \& Albrecht ED 2010 Divergent regulation of angiopoietin-1 and -2, Tie-2, and thrombospondin-1 expression by estrogen in the baboon endometrium. Molecular Reproduction and Development 77 430-438. (doi:10.1002/mrd.21163)

Brackstone M, Townson JL \& Chambers AF 2007 Tumour dormancy in breast cancer: an update. Breast Cancer Research 9 208. (doi:10.1186/ bcr1677)

Braun S, Kentenich C, Janni W, Hepp F, de Waal J, Willgeroth F, Sommer H \& Pantel K 2000 Lack of effect of adjuvant chemotherapy on the elimination of single dormant tumor cells in bone marrow of high-risk breast cancer patients. Journal of Clinical Oncology 18 80-86.

Brunckhorst MK, Xu Y, Lu R \& Yu Q 2014 Angiopoietins promote ovarian cancer progression by establishing a procancer microenvironment. American Journal of Pathology 184 2285-2296. (doi:10.1016/j.ajpath.2014.05.006)

Choi YP, Kim BG, Gao MQ, Kang S \& Cho NH 2012 Targeting ILK and beta4 integrin abrogates the invasive potential of ovarian cancer. Biochemical and Biophysical Research Communications 427 642-648. (doi:10.1016/j.bbrc.2012.09.114)

D'Souza SS, Scherzinger-Laude K, Simon M, Salimath BP \& Rossler J 2012 Angiopoietin-2 inhibition using siRNA or the peptide antagonist L1-10 results in antitumor activity in human neuroblastoma. Journal of Cancer Research and Clinical Oncology 138 2017-2026. (doi:10.1007/s00432-012-1282-3)

Daly C, Pasnikowski E, Burova E, Wong V, Aldrich TH, Griffiths J, Ioffe E, Daly TJ, Fandl JP, Papadopoulos N, et al. 2006 Angiopoietin-2 functions as an autocrine protective factor in stressed endothelial cells. PNAS 103 15491-15496. (doi:10.1073/ pnas.0607538103)

Eroglu Z, Stein CA \& Pal SK 2013 Targeting angiopoietin-2 signaling in cancer therapy. Expert Opinion on Investigational Drugs 22 813-825. (doi:10.1517/13543784.2013.793306)

Ghajar CM 2015 Metastasis prevention by targeting the dormant niche. Nature Reviews Cancer 15 238-247. (doi:10.1038/nrc3910)

Ghajar CM, Peinado H, Mori H, Matei IR, Evason KJ, Brazier H, Almeida D, Koller A, Hajjar KA, Stainier DY, et al. 2013 The perivascular niche regulates breast tumour dormancy. Nature Cell Biology 15 807-817. (doi:10.1038/ncb2767)

Giancotti FG 2013 Mechanisms governing metastatic dormancy and reactivation. Cell 155 750-764. (doi:10.1016/j.cell.2013.10.029)
Glinskii OV, Abraha TW, Turk JR, Rubin LJ, Huxley VH \& Glinsky VV 2007 Microvascular network remodeling in dura mater of ovariectomized pigs: role for angiopoietin-1 in estrogen-dependent control of vascular stability. American Journal of Physiology: Heart and Circulatory Physiology 293 H1131-H1137. (doi:10.1152/ ajpheart.01156.2006)

Goss PE \& Chambers AF 2010 Does tumour dormancy offer a therapeutic target? Nature Reviews Cancer 10 871-877. (doi:10.1038/ nrc2933)

Guo W \& Giancotti FG 2004 Integrin signalling during tumour progression. Nature Reviews Molecular Cell Biology 5 816-826. (doi:10.1038/nrm1490)

Hakanpaa L, Sipila T, Leppanen V-M, Gautam P, Nurmi H, Jacquemet G, Eklund L, Ivaska J, Alitalo K \& Saharinen P 2015 Endothelial destabilization by angiopoietin- 2 via integrin $\beta 1$ activation. Nature Communications 6 5962. (doi:10.1038/ncomms6962)

Han HH, Lee SH, Kim BG, Lee JH, Kang S \& Cho NH 2016 Estrogen receptor status predicts late-onset skeletal recurrence in breast cancer patients. Medicine 95 e2909. (doi:10.1097/md.0000000000002909)

Harfouche R, Echavarria R, Rabbani SA, Arakelian A, Hussein MA \& Hussain SN 2011 Estradiol-dependent regulation of angiopoietin expression in breast cancer cells. Journal of Steroid Biochemistry and Molecular Biology 123 17-24. (doi:10.1016/j.jsbmb.2010.09.005)

Hawighorst T, Skobe M, Streit M, Hong YK, Velasco P, Brown LF, Riccardi L, Lange-Asschenfeldt B \& Detmar M 2002 Activation of the tie2 receptor by angiopoietin-1 enhances tumor vessel maturation and impairs squamous cell carcinoma growth. American Journal of Pathology 160 1381-1392. (doi:10.1016/S0002-9440(10)62565-5)

Holopainen T, Saharinen P, D'Amico G, Lampinen A, Eklund L, Sormunen R, Anisimov A, Zarkada G, Lohela M, Helotera H, et al. 2012 Effects of angiopoietin-2-blocking antibody on endothelial cell-cell junctions and lung metastasis. Journal of the National Cancer Institute 104 461-475. (doi:10.1093/jnci/djs009)

Imanishi Y, Hu B, Jarzynka MJ, Guo P, Elishaev E, Bar-Joseph I \& Cheng SY 2007 Angiopoietin-2 stimulates breast cancer metastasis through the alpha(5)beta(1) integrin-mediated pathway. Cancer Research 67 4254-4263. (doi:10.1158/0008-5472.CAN-06-4100)

Imanishi Y, Hu B, Xiao G, Yao X \& Cheng SY 2011 Angiopoietin-2, an angiogenic regulator, promotes initial growth and survival of breast cancer metastases to the lung through the integrin-linked kinase (ILK)-AKT-B cell lymphoma 2 (Bcl-2) pathway. Journal of Biological Chemistry 286 29249-29260. (doi:10.1074/jbc.M111.235689)

Janni W, Rack B, Schindlbeck C, Strobl B, Rjosk D, Braun S, Sommer H, Pantel K, Gerber B \& Friese K 2005 The persistence of isolated tumor cells in bone marrow from patients with breast carcinoma predicts an increased risk for recurrence. Cancer 103 884-891. (doi:10.1002/ cncr.20834)

Janni W, Vogl FD, Wiedswang G, Synnestvedt M, Fehm T, Juckstock J, Borgen E, Rack B, Braun S, Sommer H, et al. 2011 Persistence of disseminated tumor cells in the bone marrow of breast cancer patients predicts increased risk for relapse - a European pooled analysis. Clinical Cancer Research 17 2967-2976. (doi:10.1158/ 1078-0432.CCR-10-2515)

Kang KS, Choi YP, Gao MQ, Kang S, Kim BG, Lee JH, Kwon MJ, Shin YK \& Cho NH 2013 CD24(+) ovary cancer cells exhibit an invasive mesenchymal phenotype. Biochemical and Biophysical Research Communications 432 333-338. (doi:10.1016/j.bbrc.2013.01.102)

Kunisaki Y, Bruns I, Scheiermann C, Ahmed J, Pinho S, Zhang D, Mizoguchi T, Wei Q, Lucas D, Ito K, et al. 2013 Arteriolar niches maintain haematopoietic stem cell quiescence. Nature 502 637-643. (doi:10.1038/nature12612)

Mandlekar S \& Kong AN 2001 Mechanisms of tamoxifen-induced apoptosis. Apoptosis 6 469-477. (doi:10.1023/A:1012437607881)

Mangan SH, Van Campenhout A, Rush C \& Golledge J 2007 Osteoprotegerin upregulates endothelial cell adhesion molecule response to tumor necrosis factor-alpha associated with induction of

Published by Bioscientifica Ltd. 
angiopoietin-2. Cardiovascular Research 76 494-505. (doi:10.1016/ j.cardiores.2007.07.017)

Marlow R, Honeth G, Lombardi S, Cariati M, Hessey S, Pipili A, Mariotti V, Buchupalli B, Foster K, Bonnet D, et al. 2013 A novel model of dormancy for bone metastatic breast cancer cells. Cancer Research 73 6886-6899. (doi:10.1158/0008-5472.CAN-13-0991)

Matsuoka-Sakata A, Tamura H, Asada H, Miwa I, Taketani T, Yamagata Y \& Sugino N 2006 Changes in vascular leakage and expression of angiopoietins in the corpus luteum during pregnancy in rats. Reproduction 131 351-360. (doi:10.1530/rep.1.00947)

McBryan J, Fagan A, McCartan D, Bane FT, Vareslija D, Cocchiglia S, Byrne C, Bolger J, Mcllroy M, Hudson L, et al. 2015 Transcriptomic profiling of sequential tumors from breast cancer patients provides a global view of metastatic expression changes following endocrine therapy. Clinical Cancer Research 21 5371-5379. (doi:10.1158/ 1078-0432.CCR-14-2155)

Mendez-Ferrer S, Michurina TV, Ferraro F, Mazloom AR, Macarthur BD, Lira SA, Scadden DT, Ma'ayan A, Enikolopov GN \& Frenette PS 2010 Mesenchymal and haematopoietic stem cells form a unique bone marrow niche. Nature 466 829-834. (doi:10.1038/nature09262)

Niu Q, Perruzzi C, Voskas D, Lawler J, Dumont DJ \& Benjamin LE 2004 Inhibition of Tie-2 signaling induces endothelial cell apoptosis, decreases Akt signaling, and induces endothelial cell expression of the endogenous anti-angiogenic molecule, thrombospondin-1. Cancer Biology \& Therapy 3 402-405. (doi:10.4161/cbt.3.4.735)

Ottewell PD, Wang N, Brown HK, Reeves KJ, Fowles CA, Croucher PI, Eaton CL \& Holen I 2014 Zoledronic acid has differential antitumor activity in the pre- and postmenopausal bone microenvironment in vivo. Clinical Cancer Research 20 2922-2932. (doi:10.1158/ 1078-0432.ccr-13-1246)

Reiss Y, Knedla A, Tal AO, Schmidt MH, Jugold M, Kiessling F, Burger AM, Wolburg H, Deutsch U \& Plate KH 2009 Switching of vascular phenotypes within a murine breast cancer model induced by angiopoietin-2. Journal of Pathology 217 571-580. (doi:10.1002/ path.2484)

Saharinen P, Eklund L, Pulkki K, Bono P \& Alitalo K 2011 VEGF and angiopoietin signaling in tumor angiogenesis and metastasis. Trends in Molecular Medicine 17 347-362. (doi:10.1016/j.molmed. 2011.01.015)

Schneider CA, Rasband WS \& Eliceiri KW 2012 NIH Image to ImageJ: 25 years of image analysis. Nature Methods 9 671-675. (doi:10.1038/nmeth.2089)

Schulz P, Fischer C, Detjen KM, Rieke S, Hilfenhaus G, von Marschall Z, Bohmig M, Koch I, Kehrberger J, Hauff P, et al. 2011 Angiopoietin-2 drives lymphatic metastasis of pancreatic cancer. FASEB Journal 25 3325-3335. (doi:10.1096/fj.11-182287)

Sfiligoi C, de Luca A, Cascone I, Sorbello V, Fuso L, Ponzone R, Biglia N, Audero E, Arisio R, Bussolino F, et al. 2003 Angiopoietin-2 expression in breast cancer correlates with lymph node invasion and short survival. International Journal of Cancer 103 466-474. (doi:10.1002/ ijc.10851)

Sosa MS, Avivar-Valderas A, Bragado P, Wen HC \& Aguirre-Ghiso JA 2011 ERK1/2 and p38alpha/beta signaling in tumor cell quiescence: opportunities to control dormant residual disease. Clinical Cancer Research 17 5850-5857. (doi:10.1158/1078-0432. ccr-10-2574)

Szasz AM, Lanczky A, Nagy A, Forster S, Hark K, Green JE, Boussioutas A, Busuttil R, Szabo A \& Gyorffy B 2016 Crossvalidation of survival associated biomarkers in gastric cancer using transcriptomic data of 1,065 patients. Oncotarget article 10337. (doi:10.18632/oncotarget.10337)

White DE, Kurpios NA, Zuo D, Hassell JA, Blaess S, Mueller U \& Muller WJ 2004 Targeted disruption of beta1-integrin in a transgenic mouse model of human breast cancer reveals an essential role in mammary tumor induction. Cancer Cell 6 159-170. (doi:10.1016/ j.ccr.2004.06.025)

Ye F, Florian M, Magder SA \& Hussain SN 2002 Regulation of angiopoietin and Tie- 2 receptor expression in non-reproductive tissues by estrogen. Steroids 67 305-310. (doi:10.1016/s0039$128 \mathrm{x}(01) 00163-5)$

Zhang XH, Giuliano M, Trivedi MV, Schiff R \& Osborne CK 2013 Metastasis dormancy in estrogen receptor-positive breast cancer. Clinical Cancer Research 19 6389-6397. (doi:10.1158/1078-0432. ccr-13-0838)

Received in final form 21 June 2016

Accepted 27 June 2016

Accepted Preprint published online 27 June 2016
(C) 2016 Society for Endocrinology Printed in Great Britain
Published by Bioscientifica Ltd 